\title{
El paisaje sonoro como cápsula del tiempo: Un proyecto creativo basado en los sonidos de la primera estación de trenes de Cuenca
}

\section{The soundscape as time capsule: A creative project based on the sounds of the first train station of Cuenca}

\author{
JAVIER ARIZA-POMARETA \\ Facultad de Bellas Artes. Departamento de Arte. \\ Universidad de Castilla-La Mancha. \\ Javier.Ariza@uclm.es
}

Recibido: 18 de diciembre de 2013

Aprobado: 12 de febrero de 2014

\begin{abstract}
Resumen
Este artículo reflexiona sobre la transformación del entorno a través del paso del tiempo y cómo determinadas tecnologías al servicio de una propuesta creativa permiten la preservación y transmisión de una parte significativa de ese efímero patrimonio a generaciones futuras. Dentro de ese propósito general se presenta este proyecto particular orientado a la realización de la síntesis sonora de un paisaje urbano tan concreto como representa la estación de trenes convencionales de Cuenca -ubicada en el centro de la ciudad- que pudiera ser conservado y reproducido como un singular documento de un presente contrastable en el tiempo futuro: una memoria que interpretase el sonido como una cápsula del tiempo. Nuestro paisaje sonoro se realizó con motivo de la llegada oficial del tren de alta velocidad en 2010 a una nueva estación construida en el extrarradio de la ciudad. El objetivo de esta investigación se centró, por tanto, en generar un documento sintético que ofreciera una memoria sonora que reflejara los rasgos significativos sociales, culturales y logísticos del que fue hasta entonces el único símbolo de la comunicación ferroviaria en la ciudad de Cuenca desde 1883 hasta el final de la primera década del siglo XXI.
\end{abstract}

Palabras clave: arte sonoro, creatividad, paisaje sonoro, tiempo, memoria.

Ariza-Pomareta, J. (2015): El paisaje sonoro como cápsula del tiempo: Un proyecto creativo basado en los sonidos de la primera estación de trenes de Cuenca. Arte, Individuo y Sociedad, 27(1) 65-79

\begin{abstract}
This article reflects on the changing environment through the passage of time and how certain technologies for a creative proposal allow the preservation and transmission of a significant part of that ephemeral heritage for future generations. The general purpose of this particular project is aimed to achieve the sound synthesis of a specific and representative cityscape as the old train station in Cuenca-located in the heart of the city- that could be preserved and reproduced as an unique document of a present time, ascertainable in the future: a memory that interpret sound as a time capsule. This soundscape was made to mark the arrival of the high speed train in 2010 to a brand new station in the outskirts of the city. Therefore, the goal of this research was focused on achieving a synthetic document that provided a sound memory capable of reflecting the significant social, cultural and logistical features, of what was until then the only railway communication symbol in the city of Cuenca from 1883 to the first decade of the $21^{\text {st }}$ century.
\end{abstract}

Keywords: sound art, creativity, soundscape, time, memory. 
Sumario: 1. Introducción, 2. La memoria, el paisaje y su recuerdo, 3. El sonido del tren en el paisaje, 4. El registro sonoro como cápsula del tiempo, 5. Composición de un paisaje sonoro, 5.1. Hipótesis, 5.2. Primera fase: delimitación del área de estudio, 5.3. Segunda fase: registro de sonidos ambientales, 5.4. Tercera fase: estudio, edición y mezcla de los sonidos ambientales, 5.5. Resultado generado. 6. Conclusiones. Referencias.

Este artículo recoge resultados de la investigación del proyecto I+D titulado Recuperación de obras pioneras del arte sonoro de la vanguardia histórica española y revisión de su influencia actal (Ref.: HAR2008-04687) financiado por el Ministerio de Ciencia e Innovación (Convocatoria de ayudas a proyectos I+D 2008) en el que su autor ha participado como miembro investigador activo.

\section{Introducción}

Este artículo expone los fundamentos teóricos y prácticos que dieron contenido conceptual y metodológico a un proyecto de creación artística relacionado con ese terreno estético del arte sonoro definido como paisaje sonoro.

Nuestra investigación, parte integral de las actividades desarrolladas en un proyecto I+D ejecutado entre 2009 y 2012, se ha centrado en el carácter de la memoria en su variante documental sonora creativa, las poéticas de su transmisión y conservación técnica, y en la capacidad referencial que puede ofrecer ese contenido en un futuro no determinado. Así mismo resulta oportuno reseñar que esta investigación ha sido producida desde el ámbito de las Bellas Artes con un enfoque multidisciplinar.

\section{La memoria, el paisaje y su recuerdo}

El objetivo primordial de nuestra investigación persigue elaborar un documento que permita trasladar a un porvenir la dimensión poética de la memoria y la evocación del recuerdo de un entorno histórico cambiante y repleto de matices -como representa la estación de trenes convencionales de Cuenca- basado en el registro, edición, organización y mezcla técnica de sus sonidos característicos. Algunas obras literarias nos han servido de referencia a la hora de interpretar la condición de la memoria humana como reflejo intemporal de la realidad. El escritor Jorge Luis Borges ha sido, en este sentido, un referente esencial para dilucidar las primeras reflexiones sobre cuestiones planteadas respecto al adecuado grado de correspondencia que nuestro recuerdo artificial debería poseer respecto a la realidad.

La memoria humana, tan limitada y proclive a la erosión de los acontecimientos almacenados, observa en el olvido su mayor amenaza y en la tergiversación de lo rememorado su mayor debilidad. Por alguna razón Borges planteó en su cuento Funes el memorioso (1944) una situación tan improbable como insoportable: la capacidad humana del recuerdo en su máxima expresión, minuciosa en los aspectos más insignificantes y habilidosa en la comparación de estos con otras situaciones análogas aunque distantes en el espacio y el tiempo. Borges expuso en su relato la posibilidad singular de una memoria humana multisensorial extraordinaria que se mantenía en un estado de permanente vigilia. En su grado más extremo Funes podía evocar el recuerdo a la misma escala que la realidad: 
Esos recuerdos no eran simples; cada imagen visual estaba ligada a sensaciones musculares, térmicas, etc. Podría reconstruir todos los sueños, todos los entresueños. Dos o tres veces había reconstruido un día entero; no había dudado nunca, pero cada reconstrucción había requerido un día entero. Me dijo: Más recuerdos tengo yo solo que los que habrán tenido todos los hombres desde que el mundo es mundo. (Borges, 1993, p.14).

En este relato, sin embargo, la extraordinaria capacidad de memoria del personaje protagonista se revela finalmente inútil al encontrarse supeditada a su propia vida. Su muerte conlleva la desaparición de sus recuerdos y la imposibilidad de volver a recuperarlos para los demás. Esta circunstancia subraya, no otorga excepción, que la memoria humana posee inherente el principio de evanescencia.

Observamos cómo esta imagen de la muerte, en cuanto destrucción de la documentación, nos conduce al concepto mal de archivo tal y como lo definiera Jacques Derrida en correspondencia a una respuesta provocada por la «pulsión de muerte» (1997, p. 20) ya que según afirma: «No hay archivo sin un lugar de consignación, sin una técnica de repetición y sin una cierta exterioridad. Ningún archivo sin afuera» (1997, p. 19).

Por otra parte, el texto de Borges también conlleva la idea de que aquello que realmente hace particular a Funes no es tanto su memoria prodigiosa-una circunstancia en él connatural- sino, por contraste, la perturbación que produce en el resto de los personajes constatar que ese grado de virtud es inigualable, único e irrepetible. Por esa razón podemos conjeturar que Funes no deja de ser una metáfora de la realidad, una realidad que se nos antoja inaprensible por su dimensión, riqueza y pluralidad de sincronismos, fugacidades, simultaneidades y sucesiones. Una memoria por otra parte, tan autosuficiente como soberbia en su propia particularidad, que dificulta en un imposible - por inexistente- su contraste absoluto con otra fuente idéntica que permitiera confirmar su excelso grado de precisión.

De este modo Borges parece advertirnos que la percepción plena de la realidad es una quimera inaprensible debido a sus inagotables matices. De igual modo lo es pretender su plena representación. Esta tesis vuelve a plantearse a través de otro de sus fantásticos relatos, como es el titulado Del rigor en la ciencia (1946). En este aspecto cobra sentido la conocida sentencia que afirma que «un mapa no es el territorio» (Kendig, 1990, p. 241) que podemos trasladar a la idea principal de que la cartografía no es sino un instrumento que nos ayuda a interpretar el papel que ocupamos dentro de esa síntesis artificiosa que traducimos como nuestro entorno real. La traducción del entorno como artificio permite el desarrollo de distintas metodologías. En el ámbito sonoro podríamos destacar aquellas que se ocupan de la representación cartográfica basadas en la señalización de parámetros sonoros significativos fundamentadas en metodologías cualitativas: estudio y análisis de aspectos sociales, culturales y artísticos de un determinado lugar, territorio o ciudad (Palmese, Carles \& Alcázar, 2010).

De este modo observamos que el aspecto más pragmático de rememorar la realidad no se encuentra tanto en el intento vano de pretender su total fidelidad como en lograr destacar aspectos determinantes que tanto a nivel formal como conceptual se 
presenten relevantes. La bondad de este segundo propósito, por su singular capacidad referencial, permite en nuestro caso abordar el paisaje con técnicas instrumentales de registro focalizando su valor en el entorno acústico y su significación sonora.

La grabación sonora, como tecnología, permite la recuperación técnica de un pasado extinto: su reproducción. Este principio también es compartido por la fotografía ya que como bien ha señalado Roland Barthes «repite mecánicamente lo que nunca más podrá repetirse existencialmente» (1989, p. 31). Sin embargo, en ambas tecnologías, su condición instrumental no exime de subjetividad el gesto de la captura en ese preciso instante ya que esta se encuentra implícita en la resolución de cuestiones de índole técnico y estético. Por otra parte, no dejamos de advertir cómo los procesos de memoria técnica adolecen de los mismos problemas que caracterizan a la memoria humana: La vinculación al soporte, su fragilidad, la necesidad de un agente capaz de reproducir el recuerdo, su pérdida y la posibilidad de tergiversación (Ariza, 2006).

De este modo, la grabación del sonido del entorno urbano e industrial, objeto de nuestra investigación, no deja de atender a variables subjetivas -técnicas y estéticastan diversas como pueden representar el momento de la captura, duración de la misma, elección del punto focal, distancia a la fuente sonora, calidad y formato de la grabación, entre otras. Todas estas variables terminan por confluir en el proceso de edición y organización para su composición final. Esta, aun habiendo sido formada por la combinación de retazos sintéticos de la realidad, evoca a la misma sin pretender ser el territorio. En este sentido cabría considerar la construcción del paisaje sonoro como un relato subjetivo y artificioso basado en la elección, organización e interpretación técnica de los sonidos:

El paisaje sonoro remite a una falsedad, o quizás a una imposibilidad: la de pretender una equivalencia entre los sonidos de un entorno, de un espacio real dado, y la constituida por esos mismos sonidos, una vez grabados y organizados, en el espacio de una obra sonora en soporte mono, estéreo o multicanal. Si no se admite esa convención, los sonidos de un paisaje sonoro serán inadmisibles como representativos de esa realidad acústica de partida [...] Conviene no olvidarlo: es una composición con sonidos, lo que nos remite a técnicas y a tecnologías. Y a una sociología de la escucha. Y a una psicoacústica. Así, bajo esas consideraciones, todos los autores de este género ofrecen imágenes compuestas, terminan empleando los sonidos del entorno acústico como el más rico y plural sintetizador posible. (Iges, 2001, pp. 61-62).

No obstante, la construcción artificiosa de un paisaje sonoro guarda sintonía con algunas teorías que cuestionan el propio mundo en el que vivimos, ese que nos sirve de modelo para nuestra realidad, al juzgarlo como una imagen artificial consecuencia de la suma de otras interpretaciones. Entre estas también se encontrarían las de carácter cultural o político. Ese es el posicionamiento filosófico de un teórico como Umberto Eco quien considera necesario el cuestionar la singularidad del mundo consensuado como real atendiendo a la posibilidad de la existencia de otros probables: 
Para cotejar mundos es necesario considerar también el mundo real o actual como artificio cultural [...] El mundo actual es el que conocemos a través de una multitud de imágenes del mundo o de descripciones de estado, y estas imágenes son mundos epistémicos que a menudo se excluyen mutuamente. El conjunto de las imágenes del mundo actual es su enciclopedia potencialmente maximal y completa. (Eco, 1992, p. 218).

Por esta razón nuestro proyecto propuso la construcción de una imagen sonora probable que fuera capaz de ofrecer una fácil legibilidad e interpretación para el oyente. El carácter de legibilidad se muestra, en este sentido, análogo al expresado por Kevin Lynch (2006) con su término imaginabilidad como esa capacidad presente en determinados objetos físicos para generar una imagen vigorosa en el espectador. Sin embargo, entendemos que esta imagen -en nuestra investigación sonora- no debe limitarse a los aspectos físicos o formales sino también incidir en aquellas otras cuestiones que permitieran valorar su significación.

\section{El sonido del tren en el paisaje}

El ámbito de estudio y análisis objeto de nuestro proyecto se centró en la estación de trenes regionales de Cuenca y su periferia más cercana debido al cargado simbolismo que esta ha poseído tradicionalmente para sus ciudadanos. También se realizó ante la llegada anunciada de un acontecimiento histórico que necesariamente debería marcar un antes y un después para la comunicación de una ciudad resignada a la escasez de infraestructuras e inversiones: la llegada del tren de alta velocidad en una nueva estación. Debe pensarse que la estación convencional comunicaba directamente solo con dos capitales de provincia: Madrid y Valencia. Para las restantes capitales, incluidas las de la propia comunidad, era preciso realizar largos transbordos. Las condiciones del viaje, la duración del mismo, la frecuencia y los horarios contribuían a enfatizar la sensación de rodeo, aislamiento y abandono atribuidas a esta ciudad con respecto al resto del territorio (Redondo, 1992, pp. 122-123).

De este modo, observamos el tren como un medio de comunicación pero también como un símbolo de la condición humana y la imagen alegórica que desprende encuentra su reflejo en la creación artística. El tren fue percibido por las vanguardias como metáfora del movimiento y de la velocidad. El principal fundador y teórico del Futurismo, F. T. Marinetti, se refirió en numerosas ocasiones al ferrocarril y la locomotora como uno de los principales símbolos de una nueva estética contemporánea. En su manifiesto La nueva religión-moral de la velocidad (1916) Marinetti llegó a definirlos como «lugares habitados por la divinidad» siendo (algunos de ellos) los trenes, los vagones-restaurantes, las estaciones, los puentes y los túneles. En este mismo documento Marinetti describió la transformación del paisaje desde esa perspectiva que sólo desde la propia máquina lanzada a toda velocidad es posible percibir. En su manifiesto los aspectos visuales se conjugan con los sonoros: 
Engranaje veloz de las ruedas del tren con dientes fuentes de ruido. Los dientes extraen de la tierra todos los ruidos que duermen en la materia. Bajo la presión del tren, los raíles saltan, vibran en la red brillante, elástica, del instante conmovido. (San Martin, 1992, p.212).

A lo largo del siglo XIX el tren trasformó paulatinamente el paisaje mundial. Las vías metálicas asemejaban cicatrices que otorgaban una nueva personalidad al territorio y el sonido industrial del ferrocarril adoptó una condición viajera e intempestiva. Para algunos autores, como el musicólogo canadiense R. Murray Schafer, el desarrollo industrial fue percibido como una amenaza creciente que atentaba contra el sonido natural razón por la cual se observaba la necesidad de su preservación mediante la sensibilización del oyente hacia el ambiente sonoro. Ese es el principal carácter que presenta su conocido libro The Tuning of the World (1977), uno de los pilares de la ecología acústica. No obstante, en su obra no deja de percibirse una cierta asimilación del sonido industrial como una parte de la actividad humana que, en definitiva, se muestra tan vulnerable y fugaz al paso del tiempo como cualquier otro sonido de condición natural. Esta transformación del paisaje sonoro industrializado termina por generar inesperadas empatías con los nuevos sonidos acontecidos e incluso llega a exponer una cierta melancolía y reconocimiento social y cultural por algunos de ellos. De este modo Schafer reconoce que «de todos los sonidos de la revolución industrial el de los trenes parecen haber tomado a través del tiempo las asociaciones sentimentales más atractivas» (1997, p.81). El listado de sonidos, enunciados en este sentido por Schafer, es amplio:

Por comparación con los sonidos del transporte moderno, los de los trenes fueron ricos y característicos: el silbido, la campana, el lento arranque de la maquinaria al principio, el rápido aceleramiento de las ruedas patinando, seguidamente de nuevo lentas, las repentinas explosiones del vapor escapando, los chirridos de las ruedas, el ruido de los vagones, el traqueteo de las vías, el golpe de aire contra la ventana cuando otro tren se cruza en dirección contraria. Todos ellos fueron sonidos memorables. (Schafer, 1977, p.81).

Cabría por tanto pensar en la pertinencia de preservar estos sonidos de la memoria del hombre en su etapa industrializada dado que estos también son caducos, efímeros y susceptibles de constituir parte de un patrimonio histórico. Por esta razón resulta muy instructiva esta advertencia que indica que «podíamos haber entrado en una era en la cual la prevención del sonido podría muy bien ser tan importante como su producción» (Schafer, 1969, p.71). Esa es la motivación que ha impulsado a diversos artistas a registrar sonidos de una tecnología reciente pero ya obsoleta con el ánimo de mantener vigente su memoria. Una referencia en este sentido la representa la iniciativa personal de Brendan Chilcutt iniciada en 2012 a través de su museo virtual de los sonidos perdidos (http://savethesounds.info).

De igual modo, los sonidos del tren anteriormente descritos por Schafer (correspondientes a la máquina de vapor), son sonidos que evidencian una cierta arqueología cuando, hoy día, un espectro amplio de la sociedad actual -la más jovense encuentra vivenciando una realidad del tren muy diferente. El aspecto cultural, 
social y político en el que se ubica el individuo juega un papel determinante la adecuada interpretación y comprensión del entorno que percibe. Resulta evidente comprobar que la transformación del paisaje sonoro en relación al ferrocarril se mostró imparable desde la revolución industrial hasta nuestros días afectando incluso a la completa transformación de sus infraestructuras más consolidadas como líneas, trenes y estaciones consecuencia de formas alternativas de viajar y consiguiente reestructuración de las existentes (Popa-Liseanu, 2010, pp. 51-67).

La estación se ofrece como la primera de las arquitecturas símbolo del viaje en ferrocarril. El tren se percibe como un agente que irrumpe en el paisaje y lo transforma. Ambas terminan por constituirse en metáforas de la vida del hombre y del paso del tiempo. Así se encuentra percibido, por ejemplo, en la obra La bête humaine (1890) de Émile Zola. Algunas de las greguerías de Ramón Gómez de la Serna que aparecen en la edición de César Nicolás se centran en la dimensión del sonido y el paisaje: «tan cerca sonaban los trenes aquella noche que parecían pasar por el túnel de nuestro corazón» (1991, p. 197); «en la noche acústica se oyen los lejanos trenes que pasan diciendo "que te cojo, que-te-cojo, que-te-cojo", persiguiendo las distancias» (1991, pp. 225-226). Marinetti también lo observó como un símbolo depurativo: «todo tren se lleva consigo la parte nostálgica del alma de quien lo ve pasar» (San Martin, 1992, p. 212). Por otra parte, algunos autores como Duran i Escribà han llegado a observar la transformación de algunas estaciones reconvertidas en Museos -es el caso de la estación del Quai d'Orsay de París- como un valor que trasciende al de las obras expuestas en su interior ya que esa circunstancia «parece actuar como metáfora de esta unión entre ferrocarril y algunos sectores artísticos» (2008, p. 155).

El planteamiento conceptual de nuestro proyecto contempló ambas dimensiones de la imagen del tren y la estación: la grabación de sonidos con una intención documental, cultural y antropológica sin obviar la vertiente metafórica del contenido a través de su organización técnica en cuanto obra creativa de carácter subjetivo.

\section{El registro sonoro como cápsula del tiempo}

El sonido es la expresión acústica del acontecimiento físico que lo provoca: el efecto se encuentra vinculado permanentemente a su causa. Pero su dimensión temporal es limitada, fugaz y tendente a su desaparición. De igual modo, extinguida la causa se presenta imposible la escucha de su efecto. Por otra parte, la audición de un sonido natural cualquiera se encuentra condicionada por la cercanía del oído a la fuente que produce el sonido, las condiciones concretas de su escucha, y la imposibilidad de volver a reproducirlo para un mejor entendimiento o percepción. Por esa razón, los mecanismos técnicos de registro adquieren un protagonismo fundamental para la preservación del sonido y su liberación en el espacio y del tiempo en que fueron producidos. Esto se consiguió mediante su grabación, o fijación (Chion, 2002), a un determinado soporte, bien digital o analógico, que lo presenta estable y duradero. El soporte se convierte de este modo en un instrumento contenedor para la transmisión de la memoria y el valor social y cultural de ese patrimonio inmaterial en otra época irrecuperable. De igual modo el soporte sonoro -contenedor- adquiere por sí mismo y por su carácter críptico unas cualidades plásticas muy valoradas en el ámbito no solo de la música sino también en el de las artes plásticas (Ariza, 2008, p. 95). 
El contenido sonoro requiere de un contenedor, un vehículo, que le permita perdurar y viajar en el tiempo. Ese es el objetivo que presentan las llamadas cápsulas del tiempo.

La cápsula del tiempo es un almacén de la memoria individual y colectiva que voluntariamente se relega al olvido con la esperanza de que llegue un mañana en el que pueda ser recuperado y su contenido expuesto y contrastado con ese nuevo tiempo presente. Se trata de un acto de abandono premeditado, una ofrenda para el futuro que exige la aceptación del paso del tiempo como requisito imprescindible para la transmisión de la memoria. La apertura de una caja del tiempo nos actualiza el pasado en nuestro presente del futuro. La actualización del recuerdo a través de la memoria como presente es observada por el filósofo Henri Bergson de este modo:

La verdad es que jamás alcanzaremos el pasado si no nos colocamos en él de golpe. Esencialmente virtual, el pasado no puede ser captado por nosotros como pasado a no ser que sigamos y adoptemos el movimiento mediante el que se abre en imagen presente, emergiendo de las tinieblas a la luz. (Bergson, 2004, p. 57).

El confinamiento de una cápsula del tiempo conlleva implícito el deseo latente de su hallazgo futuro, bien por puro azar o bien porque se han dejado claras instrucciones de su ubicación a las que se podría añadir algunas declaraciones explícitas como, por ejemplo, la de su apertura a partir de una fecha determinada. Sin embargo no hay normas para el reencuentro. El periodo de abandono es flexible y arbitrario. Algunos se estiman más próximos, otros más lejanos incluso, en su extremo, indefinidos. En cualquier caso, su recuperación -y con ella la posibilidad de revelar su contenidosuele generar un elevado grado de expectación, dado el tiempo de espera y debido al hecho de que este se produzca dentro de una nueva categoría que podríamos calificar como arqueológica programada. Algunas de estas cápsulas del tiempo, sin embargo, terminan por desvanecer su rastro por el trascurso de los años, el cambio drástico del entorno, o la simple pérdida de su referencia. Nadie es capaz de aventurar cuántas existen esperando su hallazgo de forma silenciada. Otras en cambio fueron tan célebres en el momento de su enterramiento como en el de su recuperación. Este ha sido el caso, por ejemplo, de la que ha sido catalogada como cápsula del tiempo de Steve Jobs, recientemente desenterrada en septiembre de 2013 en la localidad de Aspen tras 30 años de espera y búsqueda. Otras, no obstante, desafían el paso del tiempo con perspectivas más lejanas e inalcanzables para varias generaciones. Un claro ejemplo de ello lo representa la caja del tiempo realizada por el arquitecto Calatrava para el Museo de Historia Natural de Nueva York diseñada en 2000 y concebida para que su apertura ocurra en el año 3000. Entre los objetos almacenados se encuentra, precisamente, un disco con sonidos de la ciudad. Pero este horizonte es cercano si lo comparamos con el de cinco mil años propuestos para la apertura de la cápsula del tiempo que la empresa Westinghouse realizó con motivo de su participación en la Exposición Universal de 1939 celebrada en Nueva York. En ella se introdujeron cuarenta objetos entre los que se encontraba un microfilm conteniendo diez millones de palabras. Algunos coetáneos aventuraron en esa desorbitada dimensión temporal un futuro de logros ilimitado habida cuenta de cómo se había transformado el mundo y la tecnología en los últimos cincuenta años: 
Para calcular lo que el mundo será, no ya dentro de cinco mil años, sino dentro de mil, basta mirar atrás, a unos cien o cincuenta años solamente; en ese entonces no se conocían ni la electricidad ni sus derivados, el radio, el teléfono, la luz, la fuerza, el motor y tantos pequeños objetos que hacen dulce y agradable la vida. Para los tiempos venideros otras serán las cosas: se volará a la estratosfera, se viajará a la luna, el sueño del gran Julio Verne, y que aún ha quedado sin realización. (Echavarría, 1946, p. 66).

De la lectura queda observada cómo los logros técnicos obtenidos en el siglo xx presentaron una progresión geométrica capaz de pulverizar las expectativas más fantásticas. Tomando como referencia la fecha en la que Echavarría publicó su texto observamos cómo, tan solo veintitrés años después (el 21 de julio de 1969) el hombre hizo historia al poner su pie por primera vez en la Luna. De ello se desprende que no es preciso aparentar trascendentes con propuestas de fronteras inimaginables cuando los sucesos imprevistos relevantes son susceptibles de presentarse a diario, de improviso e incluso con la condescendencia de dejarnos algunos años de vida para contarlo.

De igual modo el contenido de una cápsula del tiempo no tiene por qué ser realmente significativo para toda la sociedad; tal vez lo bastara simplemente para el propio individuo que decidió crearla. En la película Amelie (2001) se ofrece un claro ejemplo de cómo el significado emocional del recuerdo y su sentido pleno lo tiene únicamente Dominic Bretodeau, el personaje que escondió la caja con sus recuerdos siendo niño como si esta fuera un mensaje para sí mismo capaz de burlar las leyes físicas del espacio y el tiempo hasta reencontrarse con su otro yo adulto. Una cápsula del tiempo no ha de ser sofisticada por esa razón. No atiende a la consideración de artefacto. Un objeto simple y humilde como una simple caja de cartón puede poseer esa misma connotación. Sin embargo la carcasa, y su carácter continente, parece obtener una especial atracción debido a su carácter críptico y aparentar la antesala de un interior todavía por descubrir. Una caja de madera, una lata de conservas, una tubería de hormigón, han sido, entre muchos otros, los contenedores utilizados. Cabría considerar tal vez otros continentes y la valía de estos como almacenes del recuerdo. De este modo, y por extensión, consideramos que un CDROM o un lápiz de memoria, por ejemplo, también cumplen una función como cápsula del tiempo para el almacenamiento de información electrónica sea esta un archivo de imagen o de sonido. En su dimensión más extrema podríamos considerar la ubicación de los archivos electrónicos en la red Internet como un (no) lugar al que confiar el olvido programado del documento y una determinada URL como referencia para su enclave.

\section{Composición de un paisaje sonoro}

Uno de los aspectos más reseñables que debe encontrarse presente en la composición de un paisaje sonoro, según expresa Barry Truax (2001, p. 237), es la relación de los sonidos con su contexto ambiental. El planteamiento creativo de nuestra obra parte de la acotación espacial de una zona de estudio donde registraremos información sonora significativa. Esta área específica se encuentra definida por la propia estación de trenes convencionales de Cuenca y su periferia más anexa.

Los elementos acústicos tratados derivan en conceptos inherentes al contexto del tren: el viaje, la espera, los tránsitos, los transbordos, mecanismos de comunicación, 
etc. La elección de estos sonidos ofrece al oyente una percepción acústica que permite establecer relaciones nítidas con la imagen mental a la que puede corresponder.

Asimismo la composición sonora se previó como el resultado de un proceso de mezcla y edición de los distintos sonidos registrados en los que también debían intervenir el carácter subjetivo y la dimensión artística. Es preciso puntualizar esta observación ya que el posicionamiento que ocupamos no es el de un compositor en su término más ortodoxo sino, como afirma Ruiz de Samaniego al referirse a las obras de John Hudak, el «de un artista que reflexiona sobre la naturaleza poética, temporal y evocativa de los sonidos» (2004, p. 98).

El diseño de nuestro paisaje sonoro respondió al intento de representación de un tiempo de ficción de veinticuatro horas de actividad sonora en el entorno de la estación en una síntesis creativa temporalmente comprimida en dieciséis minutos y doce segundos: tiempo medio que un transeúnte tarda en recorrer el perímetro de la zona acotada para nuestro estudio. En gran medida nuestra metodología experimental se sitúa en la misma senda en la que se encuentra la obra de audio documental Weekend (1930) de Walter Ruttman, en la cual un tiempo de ficción de cuarenta y ocho horas se presenta resumido en unos escasos once minutos de mezcla sonora. Es importante volver a subrayar el carácter fundamental que presenta la legibilidad de la información para su utilidad futura como memoria:

El paisaje sonoro será un medio desordenado o "ruidoso" en la medida que no tengamos la competencia para discriminar y jerarquizar la información allí contenida. Sin embargo, una vez que somos capaces de interpretar estos patrones sonoros de comunicación, esta asociación sobrevivirá inconscientemente a través del tiempo, siendo reactivados por nuestra memoria auditiva. (Barrie, 2006, sin paginar).

\subsection{Hipótesis}

Nuestro proyecto de investigación atendió al desarrollo de estas dos hipótesis:

El sonido es una materia plástica que se puede editar, cortar, pegar y mezclar con el objeto de crear una obra artística que interprete la dimensión acústica del entorno.

El paisaje sonoro es un documento que ofrece con el paso del tiempo su dimensión sociocultural.

\subsection{Primera fase: delimitación del área de estudio}

El proyecto se centró en la estación de trenes convencionales de Cuenca con el objeto de la preservación sonora de sus sonidos significativos y la intención de crear un documento para la memoria que permitiera, al mismo tiempo, apreciar la intención creativa y artística de la estructura sonora que le daba contenido.

De este modo se comenzó delimitando el área de estudio: se utilizó una imagen satélite de la zona y sobre ella se trazó la superficie sobre la cual trabajar; una superficie que pasamos a denominar «área estación trenes» (a partir de este punto AET). 
Nuestro objeto de estudio quedó delimitado y espacialmente circunscrito en el siguiente perímetro urbano: Paseo del Ferrocarril; calle del Orégano; calle Álvaro de Luna; Paseo de San Antonio; y paso a nivel con barreras.

\subsection{Segunda fase: registro de sonidos ambientales}

Se realizó una cuidada planificación de las distintas zonas presentes en AET. De una forma regular y constante se realizaron múltiples grabaciones de campo en distintos días durante los meses de octubre, noviembre y diciembre de 2009, tanto en el perímetro AET como en lugares concretos dentro de él. Las grabaciones, en modo estéreo, registraron tanto ambientes exteriores, como interiores. De este modo se registraron sonidos en los andenes, en el interior de la estación (tanto en la zona de expedición de billetes como en la sala de espera), en la zona exterior previa a la entrada a la estación, zona de aparcamiento de vehículos, sonidos ambientales en distintas zonas periféricas dentro del perímetro señalado, bajada y subida de las barreras en el paso a nivel, sonidos del tráfico circundante, recorridos por las vías, sonidos característicos de la actividad de la estación, vestíbulo, pasillos, compra de billetes, llegada y salida de trenes, pasajeros con sus equipajes, transbordos, locuciones por megafonía, instrucciones del jefe de estación a los trenes, sonidos de los relojes de la estación, etc.).

Asimismo se realizó y grabó en tiempo real un completo soundwalk iniciado en la misma puerta exterior de acceso a la estación en dirección al Paseo del Ferrocarril hasta completar el perímetro AET atravesando el paso a nivel sin barreras hasta llegar al apeadero de la estación por el andén interior. El tiempo que se tardó en realizar este recorrido fue de 16 minutos y 12 segundos. Dado que la extensión de la obra acústica que generase este proyecto de investigación debía de estar acotada en un tiempo concreto se predeterminó que el tiempo invertido en este recorrido debería fijar el tiempo total de la obra sonora una vez editada y mezclada. Debemos señalar que el concepto de soundwalk -derivado posteriormente como método- fue desarrollado en los años setenta por Hildegard Westerkamp y se fundamenta en la escucha silenciosa, con su posible registro técnico, del ambiente acústico que rodea al individuo a través de un determinado recorrido. La intención subyacente en esta propuesta radica en plantear la escucha como una herramienta a través de la cual analizar tanto los aspectos físicos como psicológicos que se pueden experimentar, percibir o identificar (Sharma, 2006, p. 139).

Los sonidos se registraron a través de un equipo de grabación portátil Roland; concretamente el Edirol R-09 HR. Este equipo fue escogido por su ligereza de peso $(200 \mathrm{~g})$, su alta calidad de grabación (hasta $24-$ bit/96kHz linear PCM), y un reducido tamaño (ancho: $62 \mathrm{~mm}$; alto: $113 \mathrm{~mm}$; profundidad: $27 \mathrm{~mm}$ ). Estas cualidades técnicas y físicas fueron muy valoradas en el proyecto dada la discreción visual de los medios utilizados que posibilitaron realizar grabaciones sin condicionar o afectar en modo alguno el comportamiento natural de las personas que pudieran encontrarse dentro del área de estudio al pasar completamente desapercibidos. El material sonoro obtenido ofrecía un valor documental fidedigno de la zona AET. 


\subsection{Tercera fase: estudio, edición y mezcla de los sonidos ambientales}

Se realizó durante los meses de enero y febrero de 2010 y se trató, sin duda, de la fase más laboriosa del proyecto ya que en ella se realizaron repetidas audiciones del amplio material registrado con el objeto de contemplar los aspectos más significativos de los mismos. Esta actuación precisó una gran inversión de tiempo y derivó en una selección previa de la materia prima. Algunas grabaciones fueron finalmente desestimadas por su carácter redundante.

Las audiciones permitieron seleccionar fragmentos concretos que fueron extraídos, con programas de edición de audio, y guardados como archivos independientes. A este respecto señalaremos que fueron escasas las muestras de sonido originales a las cuales no se les extrajo parte de su contenido. Los motivos no fueron tanto técnicos como de mera redundancia del material registrado que no aportaba mayor información a la ya existente. Es preciso señalar que los sonidos registrados no fueron seleccionados tanto por su valor acústico en cuanto objeto sonoro (Schaeffer, 1988), como por su valor cualitativo.

La estructura de la obra se formalizó conceptualmente como un recorrido a través de un día completo de actividad en la estación y su periferia. Se realizó la grabación de un soundwalk que determinó la duración final de nuestra composición sonora. No obstante, y al igual que el resto de archivos de audio utilizados en el montaje final, este archivo también fue editado. En su caso la edición afectó al tiempo ya que fue comprimido a tan solo dos minutos. Esta compresión del tiempo produjo una distorsión física del sonido que es perfectamente audible en la obra. La sensación acústica es la de un paisaje sonoro que se despliega a una velocidad inusitada y que provoca un cambio de percepción del sonido ambiente.

Conceptualmente la obra está concebida para englobar un tiempo de ficción de veinticuatro horas. A lo largo de la audición se perciben golpes secos de sonido que corresponden con las grabaciones realizadas en los relojes exteriores situados en los andenes de la estación. Estos golpes de sonido indican las horas en punto y son claramente percibidos, sobre todo al inicio y al final, donde adquieren su mayor carga conceptual, aunque se mantienen constantes en toda la obra. La rapidez con la que se suceden podría inducir a pensar que marcan segundos cuando en realidad refieren horas.

Cada golpe de reloj representa una hora en ese tiempo de ficción: Al inicio representan el comienzo de un nuevo día, las doce de la noche, y suenan en solitario hasta la llegada del primer tren. También son claros protagonistas al final de la obra. En este caso los golpes secos indican el número de horas desde que llegó al último tren hasta la llegada de la medianoche. El desarrollo de la obra está concebido para permitir su reproducción como un bucle eterno.

La suma de materiales sonoros se hace más intensa en el segundo tercio de la obra cuando se encuentran en la estación aquellos trenes que viajan en sentidos opuestos por distintas vías, de Madrid a Valencia y de Valencia a Madrid. Esta imagen sonora representa el papel de nexo en las comunicaciones que posee la ciudad de Cuenca para el Levante español.

Algunos sonidos presentes en la obra son incidentales. Los oídos más atentos escucharán, antes de la salida del último tren, el sonido de un teléfono que recibe 
una llamada (una llamada que no se contestó) y a los pocos segundos un sonido característico de haber recibido un mensaje en el móvil. El teléfono era el mío propio y el suceso aconteció cuando me encontraba grabando la salida del tren. Después de escuchar todo el material grabado en la investigación decidí incluir esta grabación porque este suceso reforzaba la idea de que yo mismo también formaba parte de ese paisaje sonoro. Para contribuir a reforzar esta idea se registraron otros sonidos premeditadamente: ruido de las pisadas al caminar por la piedra granulada entre las vías del tren.

El proceso de edición, montaje y mezcla se realizó a través de los siguientes recursos técnicos:

Hardware: MacBook Pro con sistema operativo Mac OS X y procesador $2.4 \mathrm{Ghz}$ Intel Core 2 Duo.

Software: Audacity (1.3.10) para la ediciones puntual de algunos archivos de audio y Soundtrack Pro (1.1.) para edición, montaje multipista y mezclado final de la obra.

\subsection{Resultado generado}

El documento generado tiene una duración de 16 minutos y 12 segundos. Ocupa una cantidad de 171,5 MB en formato de archivo de audio wave a 44,100 KHz, 16 bits y estéreo. Las características del proyecto fueron presentadas en el Teatro Auditorio de Cuenca el día 21 de noviembre de 2009 en un acto público. La obra sonora quedó latente como una cápsula del tiempo desde entonces hasta la finalización temporal del proyecto I+D en el que su autor participó como miembro investigador activo. Se estimó que pudiera ser accesible al público a la culminación del mismo.

Actualmente se puede acceder a este documento a través de su ubicación virtual en la red Internet en la dirección: http://javierarizasoundproject.blogspot.com.es

\section{Conclusiones}

La vida se compone de ricos matices y variadas sensaciones multisensoriales. Nuestra comprensión del tiempo pasado se fundamenta en el recuerdo de algunas parcelas sintéticas de esta realidad.

Algunas tecnologías y técnicas permiten aproximarnos a la utópica posibilidad de conservar la plena realidad. El producto de estos procesos técnicos deriva en el concepto de documento y archivo: un tipo de ficción basada en extractos de realidad que se construye y conserva para su disposición futura.

El documento se muestra como una memoria artificial. La consideración de memoria para el documento conlleva la susceptibilidad de que este posea algunas perversiones propias de la condición humana como son la parcialidad, la tergiversación, la subjetividad o la intencionalidad.

El archivo se ofrece como elemento contenedor y espacio de confinamiento. Las nuevas tecnologías amplifican este concepto. 
Podemos rememorar el pasado construyendo un documento artificioso que atienda específicamente al sentido del oído a través de la grabación del entorno. $\mathrm{Su}$ resultado, como paisaje sonoro, permite documentar de forma subjetiva y creativa un determinado espacio y tiempo reconocible. La singularidad del paisaje sonoro ofrece un valoración múltiple: cartográfica, psicoacústica, ecológica, social, cultural, política y artística.

El resultado de nuestro proyecto ofrece un paisaje sonoro consecuencia de la interpretación subjetiva de retazos registrados y combinados de una realidad acústica. Su duración tiene una vinculación objetiva con el área de estudio. Así mismo, el contenido sonoro permite localizar temporal y espacialmente el objeto de nuestra investigación.

El sonido codificado técnicamente se ofrece como un documento estable para su conservación en el tiempo. Nuestra obra se planteó como una cápsula del tiempo concebida para volver a ser escuchada una vez concluido el proyecto de investigación I+D que lo había originado, esto es, en cualquier momento una vez finalizado 2012.

La evocación del recuerdo admite una interpretación poética. La metáfora se establece como figura retórica que establece numerosas analogías entre la máquina y el espacio en el que esta se desenvuelve con la vida del hombre.

Consideramos que la llegada del tren de alta velocidad a la nueva estación de Cuenca Fernando Zóbel influirá determinantemente en el cambio del paisaje sonoro de la estación de trenes convencionales. Los cambios sutiles que se pueden producir gradualmente en ella podrán ser ciertamente valorados únicamente si tenemos capacidad de realizar algún tipo de comparativa con la documentación que pudiera entonces conservarse. Nuestro proyecto contribuirá a este propósito con una obra de carácter electrónico capaz de adaptarse a nuevos formatos y continentes para superar el paso del tiempo.

Por otra parte consideramos que el resultado de nuestra investigación debería contribuir al incremento de la riqueza patrimonial inmaterial de una ciudad cuyo recinto histórico fue declarado Patrimonio de la Humanidad por la Unesco el 6 de diciembre de 1996.

\section{Referencias}

Ariza, J. (2006). La ciudad y la memoria. En Lago González, E. (coord.), Pixelia 1.0. Encontro urbano de arte dixital (sin paginar). Lugo: Diputación Provincial.

Ariza, J. (2008). Las imágenes del sonido: Una lectura plurisensorial en el arte del

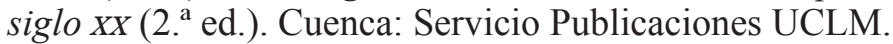

Barrie, L. (2006). El sueño de Haumaka. Un recorrido sonoro en Isla de Pascua. Santiago de Chile: Consejo Nacional de la Cultura y las Artes/FONDART.

Barthes, R. (1989). La cámara lúcida. Barcelona: Paidós.

Bergson, H. (2004). Memoria y vida. Madrid: Alianza.

Borges, J. L. (1993). Artificios. Madrid: Alianza.

Chion, M. (2002). El arte de los sonidos fijados. Cuenca: Centro de Creación Experimental.

Derrida, J. (1977). Mal de archivo. Una impresión freudiana. Madrid: Editorial Trotta. 
Duran i Escribà, X. (2008). El artista en el laboratorio: Pinceladas sobre arte y ciencia. Valencia: Servicio de Publicaciones de la Universitat de València.

Echavarría, E. (1946). Crónicas e Historia Bancaria de Antioquia. Medellín: Instituto Tecnológico Metropolitano.

Eco, U. (1992). Los límites de la interpretación. Barcelona: Lumen.

Iges, J. (2001). Un approcio alla storia del paesaggio sonoro. Musica / Realtà, (65), pp. 55-66.

Kendig, M. [ed.] (1990) Alfred Korzybski: Collected Writings, 1920-1950. Pittsboro: Institute of General Semantics, International Non-Artistotelian Library.

Lynch, K. (2006). La imagen de la ciudad. Barcelona: Gustavo Gili.

Nicolás, C. (ed.) (1991). Ramón Gómez de la Serna: Greguerías: selección, 19101960. Madrid: Espasa Calpe.

Palmese, C. Carles, J. L. \& Alcazar, A. J. (2010). Paisajes sonoros de Cuenca. Cuenca: Servicio Publicaciones UCLM.

Popa-Liseanu, D. (2010). La estación: un cruce de caminos. En Popeanga, E. (coord.), Ciudad en obras. Metáforas de lo urbano en la literatura y en las artes (pp. 5166). Bern: Peter Lang AG.

Redondo, G. (1992). Transporte y espacio: Cuenca, Cuenca: Diputación Provincial. Ruiz de Samaniego, A. R. (2004). La inflexión posmoderna: los márgenes de la modernidad. Madrid: Akal.

San Martin, F. J. (1992). La mirada nerviosa. Guipúzcoa: Diputación Foral.

Schaeffer, P. (1988). Tratado de los objetos musicales. Madrid: Alianza Editorial.

Schafer, R. M. (1969). El nuevo paisaje sonoro. Buenos Aires: Ricordi.

Schafer, R. M. (1977). The Tuning of the World. Nueva York: Alfred A. Knopf.

Sharma, K. (2006). Aural Rehabilitation of Hearing Impaired Children. Nueva Delhi:

Sarup \& Sons.

Truax, B. (2001). Acoustic Communication. Westport: Ablex Publishing. 